\title{
Integrated Buck-Flyback Converter with Simple Structure and Unity Power Factor
}

\author{
A. Hakeem Memon, Amad A. Pathan, Mahesh Kumar, Anwar A. Sahito and Zubair A. Memon
}

IICT, Mehran University of Engineering and Technology (UET), Indus Hwy, Jamshoro; Sindh 76062, Pakistan; hakeem.memon@faculty.muet.edu.pk,Amad_212@hotmail.com, rathii.mahesh@ faculty.muet.edu.pk, anwar.sahitoi@faculty.muet.edu.pk,zubair.memon@ faculty.muet.edu.pk,

\begin{abstract}
The dead zone in the buck converter can be eliminated by integrating flyback converter with it. However, its input Power Factor (PF) is low when operated with Constant On-Time Control (COTC). In this paper, a Variable On-Time Control (VOTC) strategy is proposed for Integrated Buck-Flyback Converter (IBFC) with simple structure to obtain unity PF. By feed forwarding input and output voltage to change the on-time of both switches, high PF can be achieved. The operating principle of the IBFC is discussed with both types of control schemes and for verifying the effectiveness of VOTC scheme; simulations are carried out by using Saber simulator.
\end{abstract}

Keywords: Constant On-Time Control (COTC), Integrated Buck-Flyback Converter (IBFC), Variable On-Time Control (VOTC) Scheme

\section{Introduction}

Power electronic technology is used in various types of modern equipment's which has made our life easier, simpler and luxurious. However, this technology is based on semiconductor devices, due to which the shape of average input current is distorted. The distorted current has various drawbacks such as voltage distortion, increased power loss and noise etc. So the industries have built various standards such as IEC61000-3-2 limit and IEEE 519'2. Therefore, various types of Power Factor Correction (PFC) converters are put forward in the literature to improve the shape of distorted current ${ }^{3-4}$ and the buck converter is one of them. Its advantages include protection against short circuit, high efficiency at universal input voltage, low output voltage, and less voltage stress on the switch. However, its input Power Factor (PF) is low due to dead zone in the average input current. Integrating buck converter with flyback converters can solve the dead zone problem and enhance its PF. However, unity P.F cannot be realized when the on-time is constant. Thus, it is necessary for the integrated buck-flyback converter to propose the technique which can realize unity PF with simple structure and minimum losses.
For modifying the performance of traditional buck converter, various researches has proposed flyback converter to integrate with it.

$\mathrm{In}^{5}$ a new solution for eliminating the dead zone in the buck converter is proposed. It has proposed flyback converter to work with buck converter during dead zone period. Integrated Buck-Flyback Converter (IBFC) for low cost, high $\mathrm{PF}$ and fast output voltage regulations is implemented in ${ }^{6}$. The study in ${ }^{7}$ has presented IBFC for single-stage electronic ballast with high PF. $\mathrm{In}^{8}$, offline IBFC for High Brightness-Light Emitting Diode (HB-LED) to cover the application of LED in street light is presented. A new topology which combines buck and flyback converter to eliminate the dead zone is put forward in ${ }^{10}$. The research in ${ }^{11}$ has proposed a topology which combines buck converter with flyback converter. $\operatorname{In}^{12}$, a control scheme is put forward to improve input PF.

In this paper, a VOTC strategy is introduced for IBFC to realize unity $\mathrm{PF}$ with minimum component cost. It requires one Bridge Rectifier (BR) and for passing the low frequency current to reduce losses, EMI filter is located after BR.

The analysis of the operating principle of IBFC converter is discussed with traditional control (COTC) 
scheme in Section 2. The VOTC is put forward in Section 3 to attain unity PF. In Section 4, simulation results are discussed and the conclusion is given in Section 5

\section{Operating Principle of IBFC}

Figure 1 illustrates the schematic diagram of an IBFC. The major components in the power circuit are: Bridge rectifier (BR); a primary inductor $\left(L_{p}\right)$; a secondary inductor $\left(L_{s}\right)$; a buck switch $\left(Q_{b}\right)$; a flyback switch $\left(Q_{f}\right)$, a freewheeling diode $\left(D_{f w}\right)$, an output capacitor $\left(C_{o}\right)$, etc.

The operating time period between buck and flyback converter depends on the boundary voltage, whose value is little more as compared to output voltage $\left(V_{o}\right)$. The IBFC operates in flyback mode as the input voltage $\left(v_{i n}\right)$ is lower than $V_{o}$ and in buck mode for opposite condition (i-e $v_{\text {in }}>V_{\text {boundary }}$ ). Thus, the operating principle of IBFC operating in critical conduction mode (CRM) can be divided into two cases

The instantaneous and rectified input voltage during half line cycle can be given as:

$$
v_{\text {in }}=v_{a}=V_{m} \sin \theta
$$

The IBFC is operating in buck mode when $v_{\text {in }}>V_{\text {boundary }}$. The flyback switch $\left(Q_{f}\right)$ remain closed while buck switch $\left(Q_{b}\right)$ keeps switching.

While $Q_{b}$ is $\mathrm{ON}$ and $L_{s}, C_{o}, R_{L d}$ conducts. The rising slope of buck inductor is:

$$
\frac{d i_{L s}}{d t}=\frac{V_{m} \sin \theta-V_{o}}{L_{s}} \quad \theta_{0} \leq \theta \leq \pi-\theta_{0}
$$

where $\theta 0=\arcsin$ Vboundary/Vm.

The peak value of inductor current is:

$$
i_{L_{-} p k}=\frac{V_{m} \sin \theta-V_{o}}{L_{s}} t_{o n}
$$

When, $Q_{b}$ is OFF and $L_{s}, C_{o}, R_{L d^{\prime}}, D_{f w}$ conducts. The falling time of buck inductor is determined as:

$$
t_{o f f}=\frac{L_{s}}{V_{o}} i_{L s_{-} p k}
$$

By substituting the value of $i_{L s_{-} p k}$ in eq. (4), we get:

$$
t_{\text {off }}=t_{\text {on }} \frac{V_{m} \sin \theta-V_{o}}{V_{o}}
$$

The total time is:

$$
t_{s}=t_{o n}+t_{o f f}
$$

By putting the (5) into (6) results in:

$$
t_{s}=\frac{V_{m} \sin \theta}{V_{o}} t_{o n}
$$

The formula to calculate the average input current of buck converter $\left(i_{\text {in_b }}\right)$ is:

$$
i_{\text {in }_{-} b}=\frac{i_{L s_{-} p k} t_{o n}}{2 t_{s}}=\frac{V_{o}\left(V_{m} \sin \theta-V_{o}\right) t_{o n}}{2 L_{s} V_{m} \sin \theta} \quad\left(\theta_{0} \leq \theta \leq \pi-\theta_{0}\right)
$$

The IBFC is operating in flyback mode when $v_{\text {in }}<V_{\text {boundary }}$. The flyback switch $\left(Q_{f}\right)$ keeps switching, while buck switch $\left(Q_{b}\right)$ remains closed.

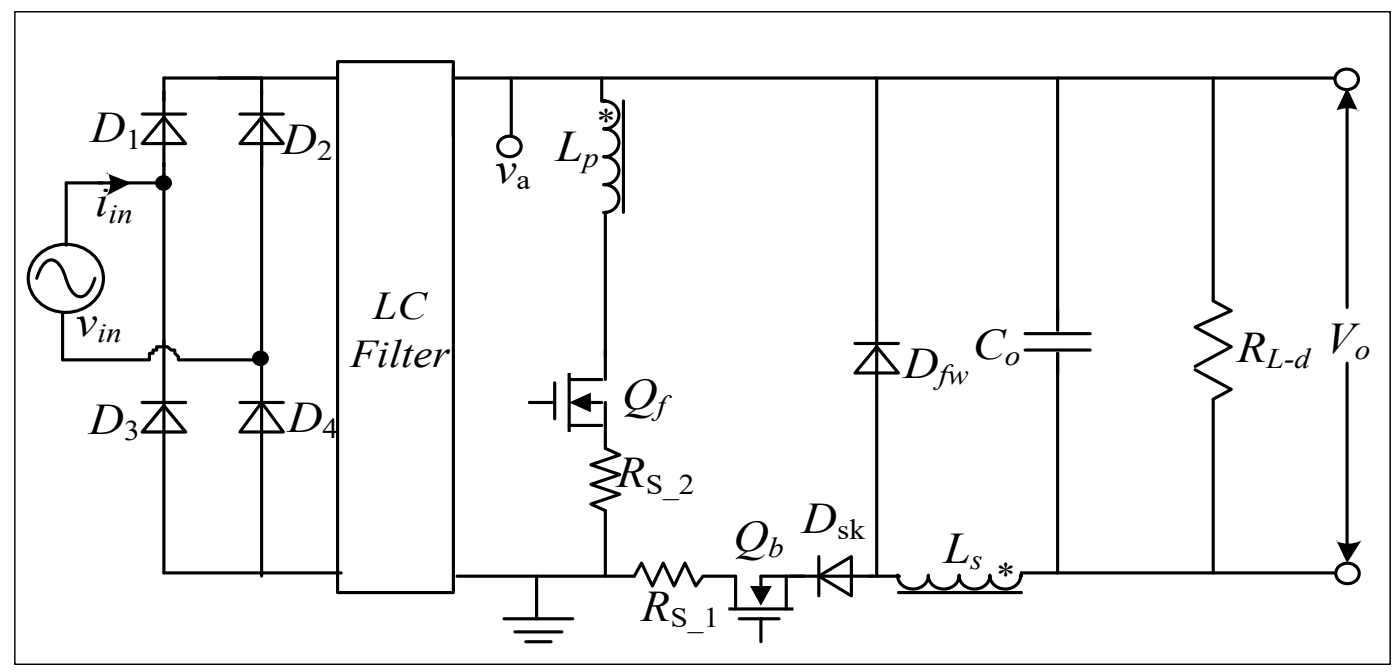

Figure 1. Schematic diagram of an IBFC. 
When $Q_{f}$ is $\mathrm{ON}$, the current flows through primary inductor $L_{p}$ and the values of inductor's rising slope and peak current are:

$$
\begin{gathered}
\frac{d i_{L p}}{d t}=\frac{V_{m} \sin \theta}{L_{p}} \quad 0 \leq \theta<\theta_{0} \& \pi-\theta_{0}<\theta \leq \pi \\
i_{L p_{-} p k}=\frac{t_{o n} V_{m} \sin \theta}{L_{p}}
\end{gathered}
$$

While, $Q_{f}$ is OFF, $L_{s}, C_{o}, R_{L d d^{\prime}} D_{f w}$ conducts and the falling slope is:

$$
\frac{d i_{L s}}{d t}=-\frac{V_{o}}{L}
$$

According to the volt-second balance, we can get the resulting equation as:

$$
t_{\text {off }}=\frac{\sqrt{L_{s}} V_{m} \sin \theta}{\sqrt{L_{p}} V_{o}} t_{o n}
$$

From (12) and (6), following relation is obtained:

$$
t_{s}=t_{o n}\left(1+\frac{\sqrt{L_{s}} V_{m}|\sin \theta|}{\sqrt{L_{p}} V_{o}}\right)
$$

The average input current of flyback converter can be expressed as:

$$
i_{i n_{-} f}=\frac{V_{m} \sin \theta}{2 L_{p}\left(1+\frac{\sqrt{L_{s}} V_{m}|\sin \theta|}{\sqrt{L_{p}} V_{o}}\right)} t_{\text {on }}
$$

By combining (8) and (14), the input current of IBFC is expressed as:

$$
i_{\text {in_CоTC }}=\left\{\begin{array}{l}
\frac{t_{\text {on }} V_{m} \sin \theta}{2 L_{p}\left(1+\frac{\sqrt{L_{s}} V_{m} \sin \theta}{\sqrt{L_{p}} V_{o}}\right)} 0 \leq \theta<\theta_{0} \& \pi-\theta_{0}<\theta \leq \pi \\
\frac{t_{\text {on }} V_{o}\left(\frac{V_{m} \sin \theta-V_{o}}{2 L_{s}}\right)}{V_{m} \sin \theta} \quad \theta_{0} \leq \theta \leq \pi-\theta_{0}
\end{array}\right.
$$

The average input power can be calculated from (1) and (15) as:

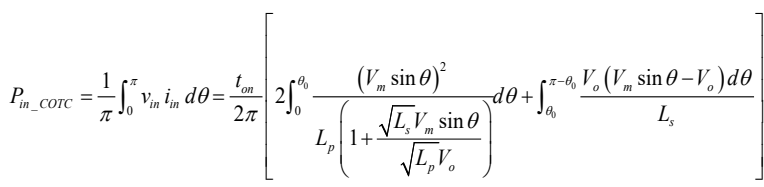

From (16), $t_{\text {on }}$ can be determined by assuming the efficiency to be $100 \%$ as:

$$
t_{\text {on }}=\frac{2 \pi P_{o}}{2 \int_{0}^{\theta_{0}} \frac{\left(V_{m} \sin \theta\right)^{2}}{L_{p}\left(1+\frac{\sqrt{L_{s}} V_{m} \sin \theta}{\sqrt{L_{p}} V_{o}}\right)} d \theta+\int_{\theta_{0}}^{\pi-\theta_{0}} \frac{V_{o}\left(V_{m} \sin \theta-V_{o}\right) d \theta}{L_{s}}}
$$

According to (15), (17) and the specification of the IBFC that are mentioned in Section 5, the input current waveforms regarding the input voltage for different ratio are shown in Figure 2. It can be observed that shape of average input current is not purely sinusoidal. Thus unity PF cannot be realized at any turns ratio.

\section{Proposed VOTC for IBFC}

\subsection{VOTC for Unity PF}

If the PF is unity, according to power balance, the input current must be:

$$
i_{i n_{-} \text {VOTC }}=\frac{2 P_{o} \sin \theta}{V_{m}}
$$

By combining (15) and (18), we can get required on-time of both switches as:

$$
\begin{aligned}
& t_{\text {on_buck }}=u_{o n 1} \frac{\left(V_{m} \sin \theta\right)^{2}}{V_{o}\left(V_{m} \sin \theta-V_{o}\right)} \\
& t_{\text {on_flyback }}=u_{\text {on } 2}\left(1+\frac{\sqrt{L_{s}} V_{m} \sin \theta}{\sqrt{L_{p}} V_{o}}\right)
\end{aligned}
$$

Where uon 1 and uon 2 is constant.

By substituting (19) into (15), we can get average input current with VOTC as:

$$
i_{\text {in_VOTC }}= \begin{cases}\frac{u_{\text {on } 2} V_{m} \sin \theta}{2 L_{p}} & 0 \leq \theta<\theta_{0} \& \pi-\theta_{0}<\theta \leq \pi \\ \frac{u_{\text {on } 1} V_{m} \sin \theta}{2 L_{s}} & \theta_{0} \leq \theta \leq \pi-\theta_{0}\end{cases}
$$

By combining (18) and (20), input current at the boundary between buck and flyback is given as:

$$
i_{\text {in_atboundary }}=\frac{u_{\text {on } 1} V_{m} \sin \theta_{0}}{2 L_{s}}=\frac{u_{\text {on2 } 2} V_{m} \sin \theta_{0}}{2 L_{p}}=\frac{2 P_{o} \sin \theta_{0}}{V_{m}}
$$




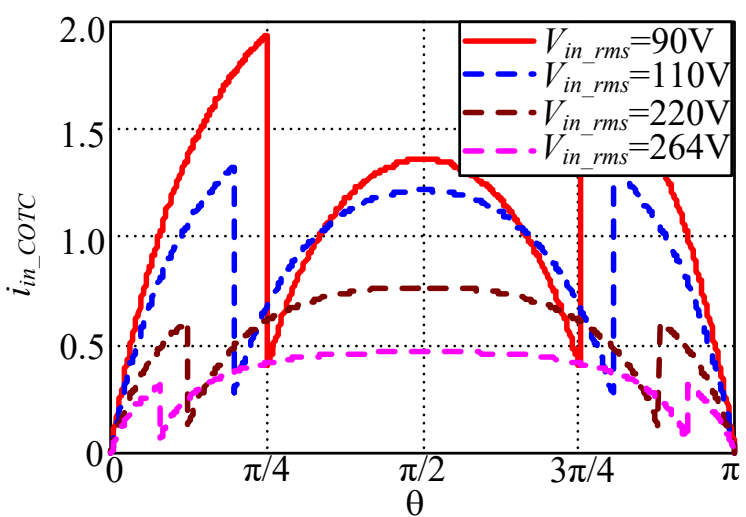

(a)

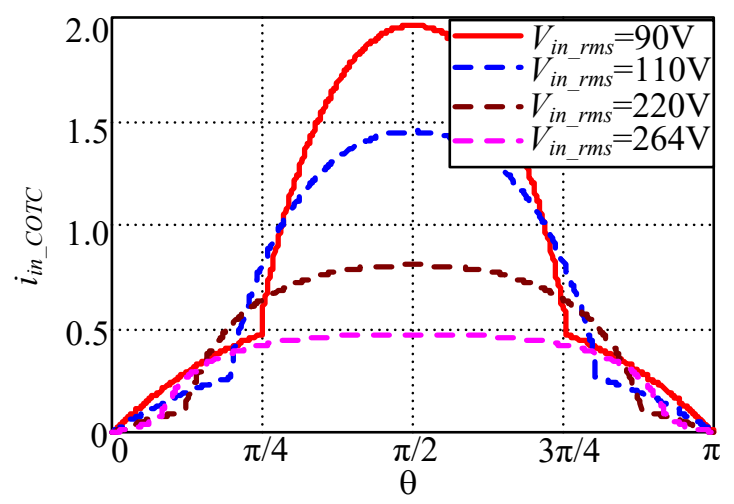

(c)

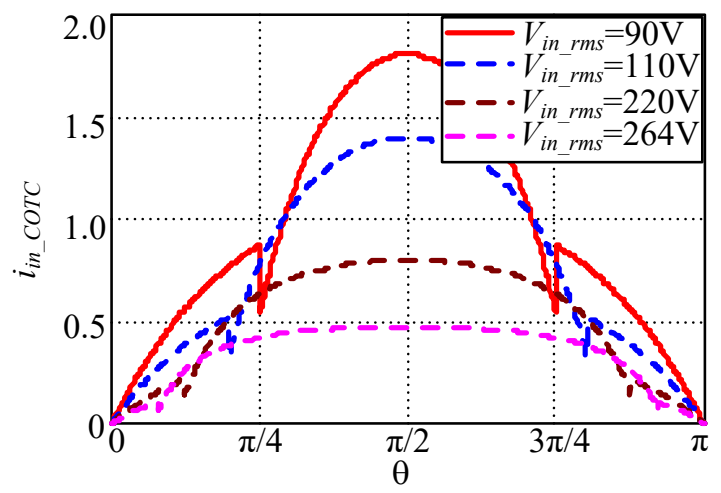

(b)

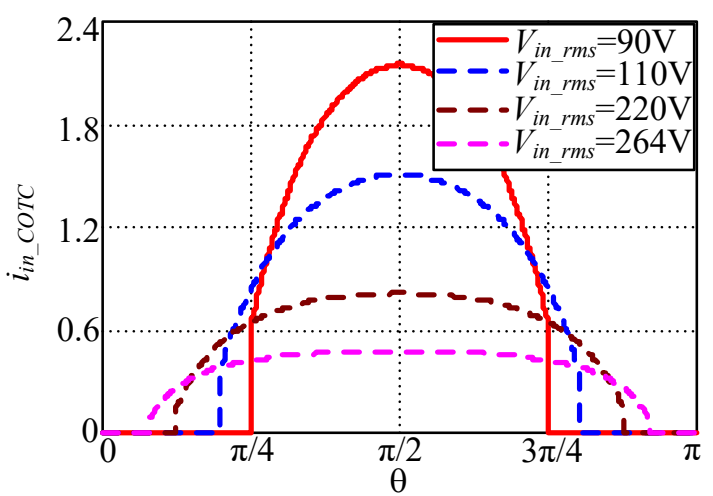

(d)

Figure 2. Average input current waveform: (a) $n=1$; (b) $n=2$; (c) $n=3$; (d); $n=100$.

Thus,

$$
\begin{aligned}
& u_{o n 1}=\frac{4 P_{o} L_{s}}{V_{m}^{2}} \\
& u_{o n 2}=\frac{4 P_{o} L_{p}}{V_{m}^{2}}
\end{aligned}
$$

By substituting (22) into (19), we get:

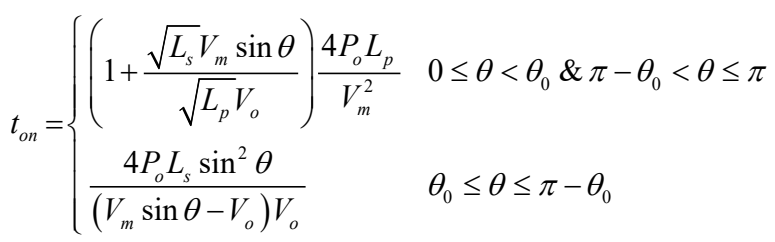

\subsection{Implementation Circuit}

The control circuit can be implemented as shown in Figure 3. The rectified input voltage $v_{g}$ is sensed through a voltage divider circuit of $R 1$ and $R 2$, and $v_{A}=k 1 V_{m} \sin \theta$, where $\mathrm{k} 1=\mathrm{R} 2 /(\mathrm{R} 1+\mathrm{R} 2)$ is the voltage sensor gain.

By sensing the $V_{o}$ with the output sensor gain results in $v_{B}=\mathrm{k} 2 V_{o}$,

where $k_{2}=\frac{R_{6}\left(\frac{R_{3} V_{o}}{R_{3}+R_{4}}-V_{e b}\right)}{R_{5} V_{o}}$

The implementation circuit of VOTC scheme for buck converter is depicted in the region of brown dotted line and multiplier 1's output is $v_{C}=v_{A}^{2} / v_{B}$.

$v_{B}$ is compared with the reference voltage $\left(V_{r e f}\right)$. The compensation network is formed by $C 1, C 2$, and $R 13$. The output of error amplifier is $v_{E A_{-} \text {buck }}$. The input to multiplier 2 are $V_{C}$, and $v_{E A \_b u c k}$ and the output is $v_{D}=v_{E A \_b u c k} v_{A}^{2} / v_{B}$.

The function of series resistor $\left(R_{s_{-}} 1\right)$ is to sense buck switch's current. The inputs to the comparator are $v_{D}$ and voltage across current sensor. The comparator's output and zero current detection winding (ZCD) cause the buck switch to operate in VOTC. 


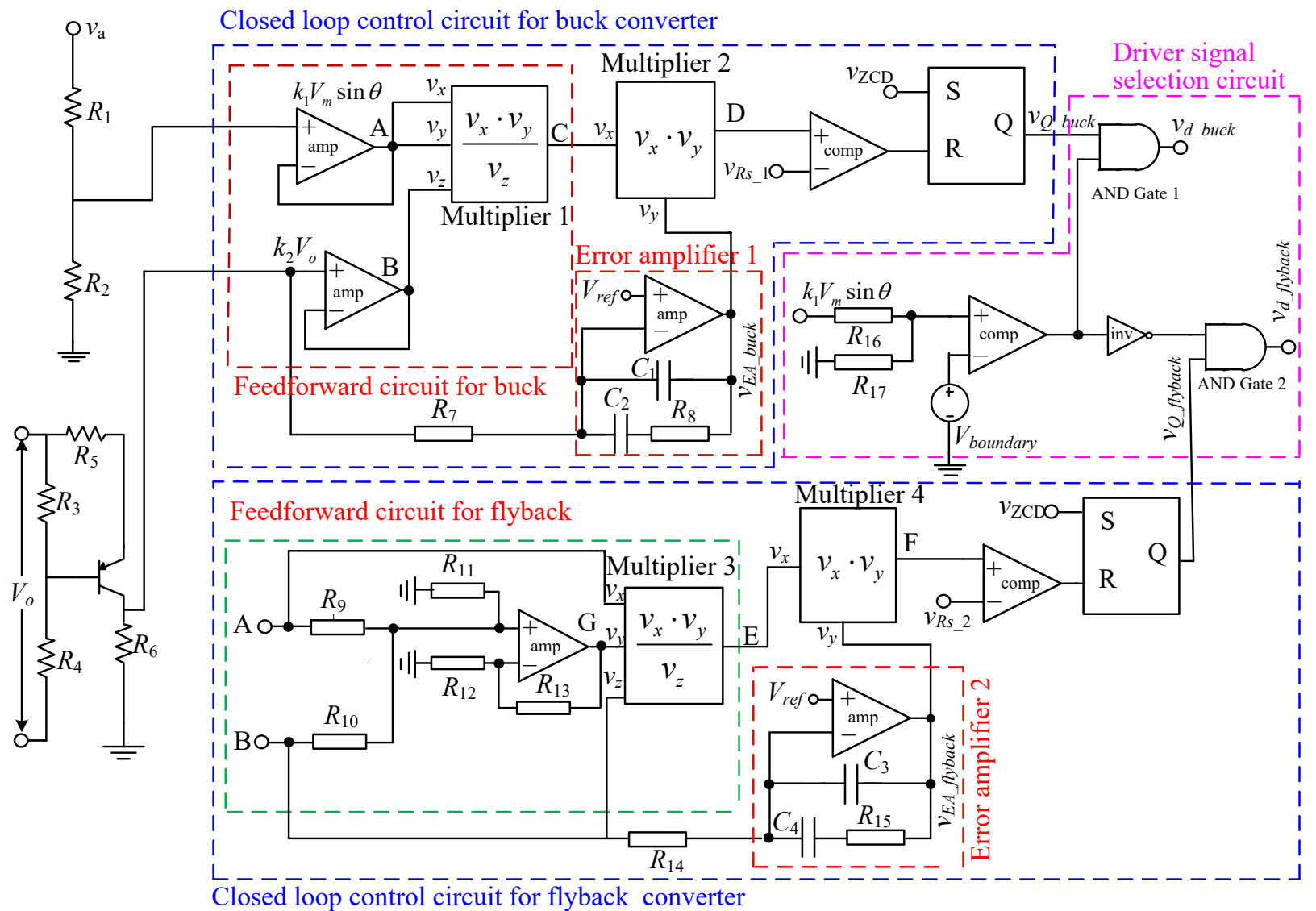

Figure 3. Feed forward circuit for VOTC.

The implementation circuit of VOTC scheme for flyback converter is illustrated in the region of green dotted line and multiplier 3's output is $v_{E}=v_{A}\left(v_{A}+v_{B}\right) / V_{o}$.

$C 3, C 4$, and $R 15$ compose the compensation network, $V_{E}$, and $v_{E A_{f} f l b a c k}$ are sent to multiplier 4, and the output of multiplier is $v_{F}=v_{E A \_f l y b a c k} v_{A}\left(v_{A}+v_{B}\right) / V_{o}$.

Same as buck converter, the function of series resistor $\left(R_{s_{-}} 2\right)$ is to sense flyback switch's current. The inputs to the comparator are $v_{E}$ and voltage across current sensor. The comparator's output and Zero Current Detection (ZCD) winding cause the flyback switch to operate in VOTC.

To realize unity $\mathrm{PF}$ at specific turn's ratio, following condition should be satisfied by proper selecting the values of the resistors.

$$
k_{2}=k_{1} \sqrt{\frac{L_{s}}{L_{p}}}
$$

\section{Simulation Results}

For verifying the effectiveness of VOTC strategy, simulations are carried out. The input voltage range is 90-264VAC, and the output is $80 \mathrm{~V}$. For ensuring the current to be in CRM, L6561 IC is used. All the components in the circuit are selected as idea.

Figure 4 and 5 show the simulation waveforms of $v_{i n}$ $\mathrm{i}_{\text {in }}$, and $v_{o}$ of IBFC with COTC and VOTC at 220VAC inputs, respectively. It can be observed that the input current with VOTC is more sinusoidal as compared with COTC. The input current waveform with VOTC is nearly sinusoidal, so unity PF can be obtained.

Figure 6 shows the switches' gate drive signals of the converter, from which it can be seen that in both types of control schemes, the converter operates either in buck mode or in flyback mode depending on the boundary voltage between them. 


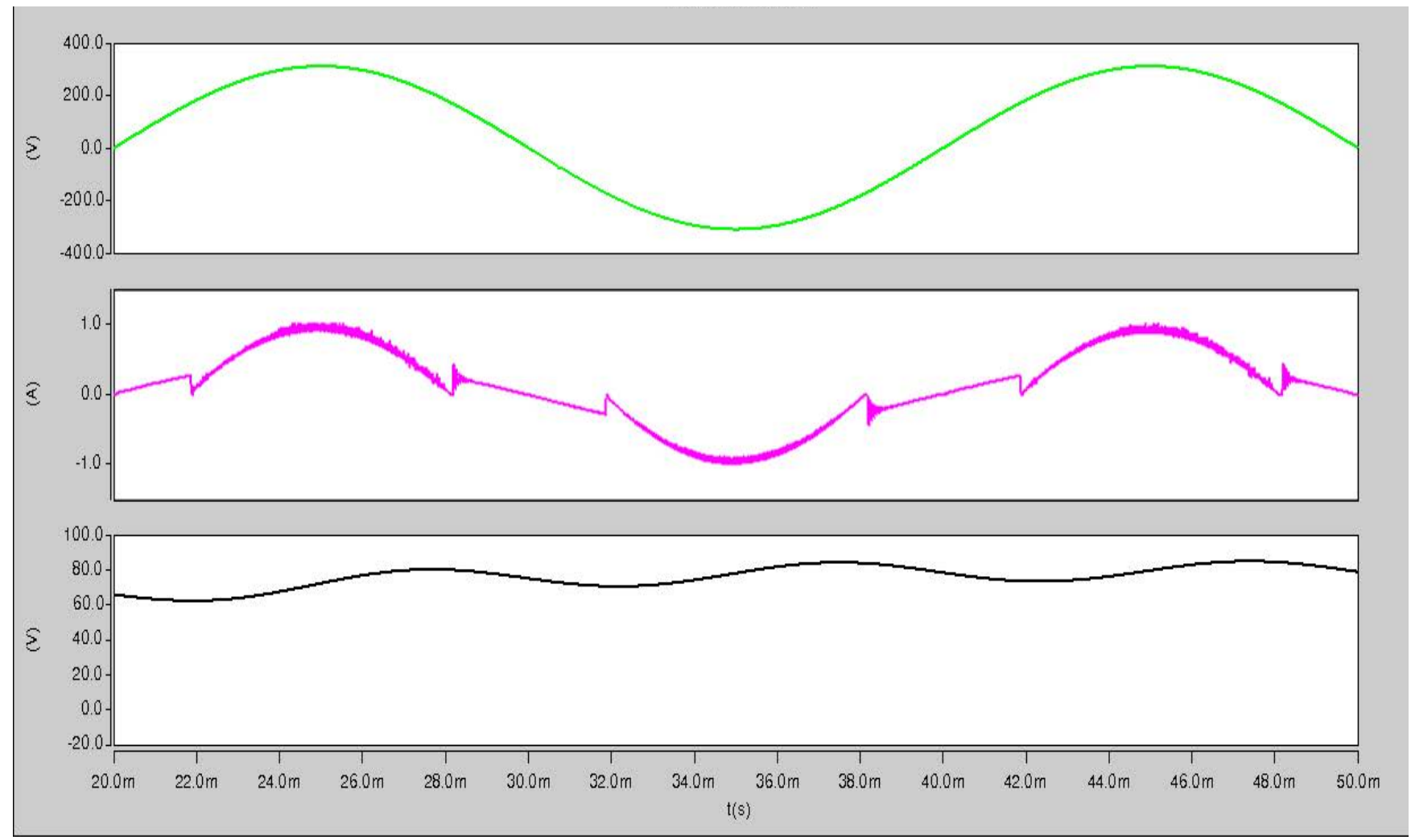

Figure 4. $v_{i n}$, iin, and $v_{o}$ with COTC.

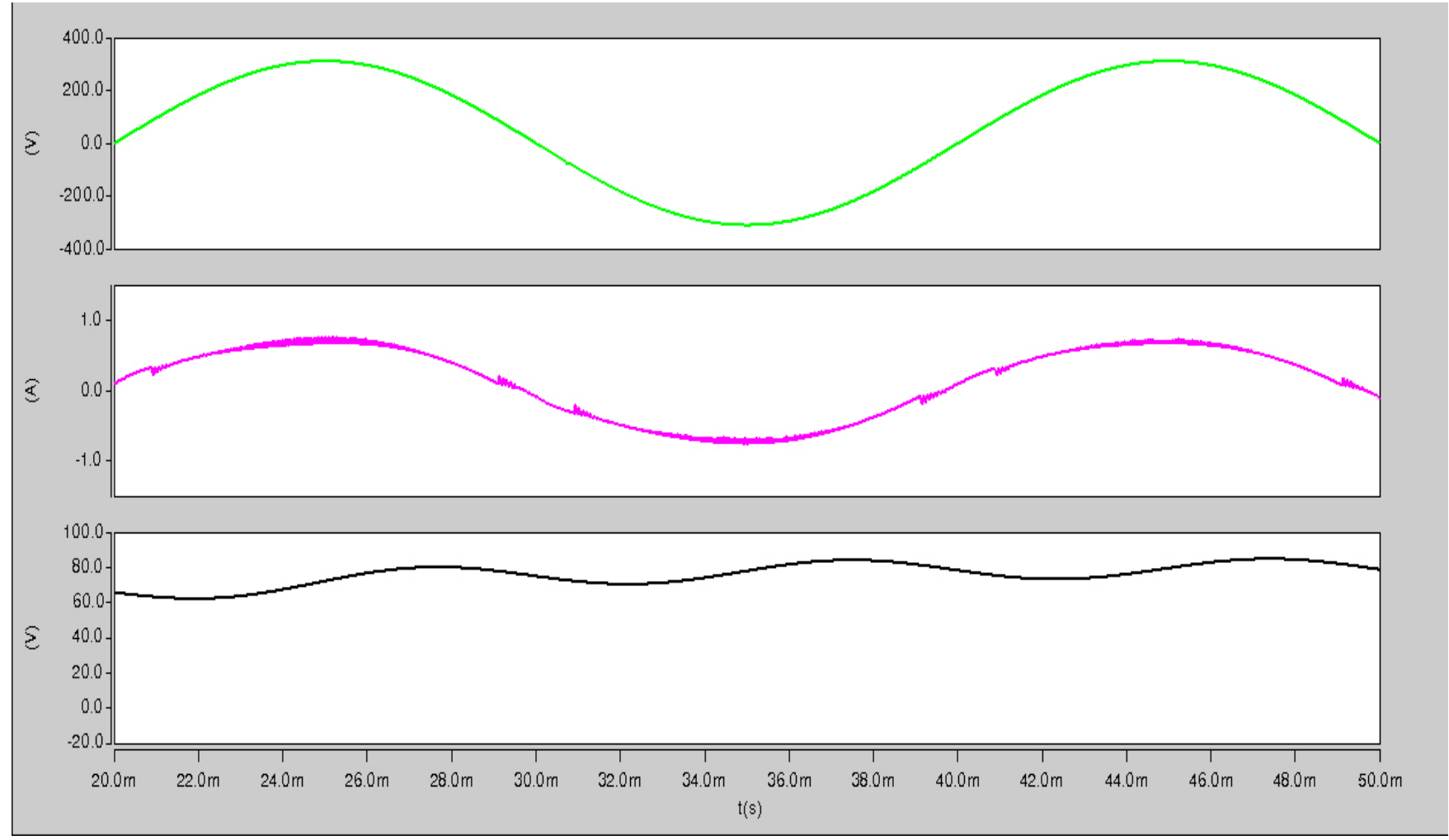

Figure 5. $v_{i n}$, iin, and $v_{o}$ with VOTC. 


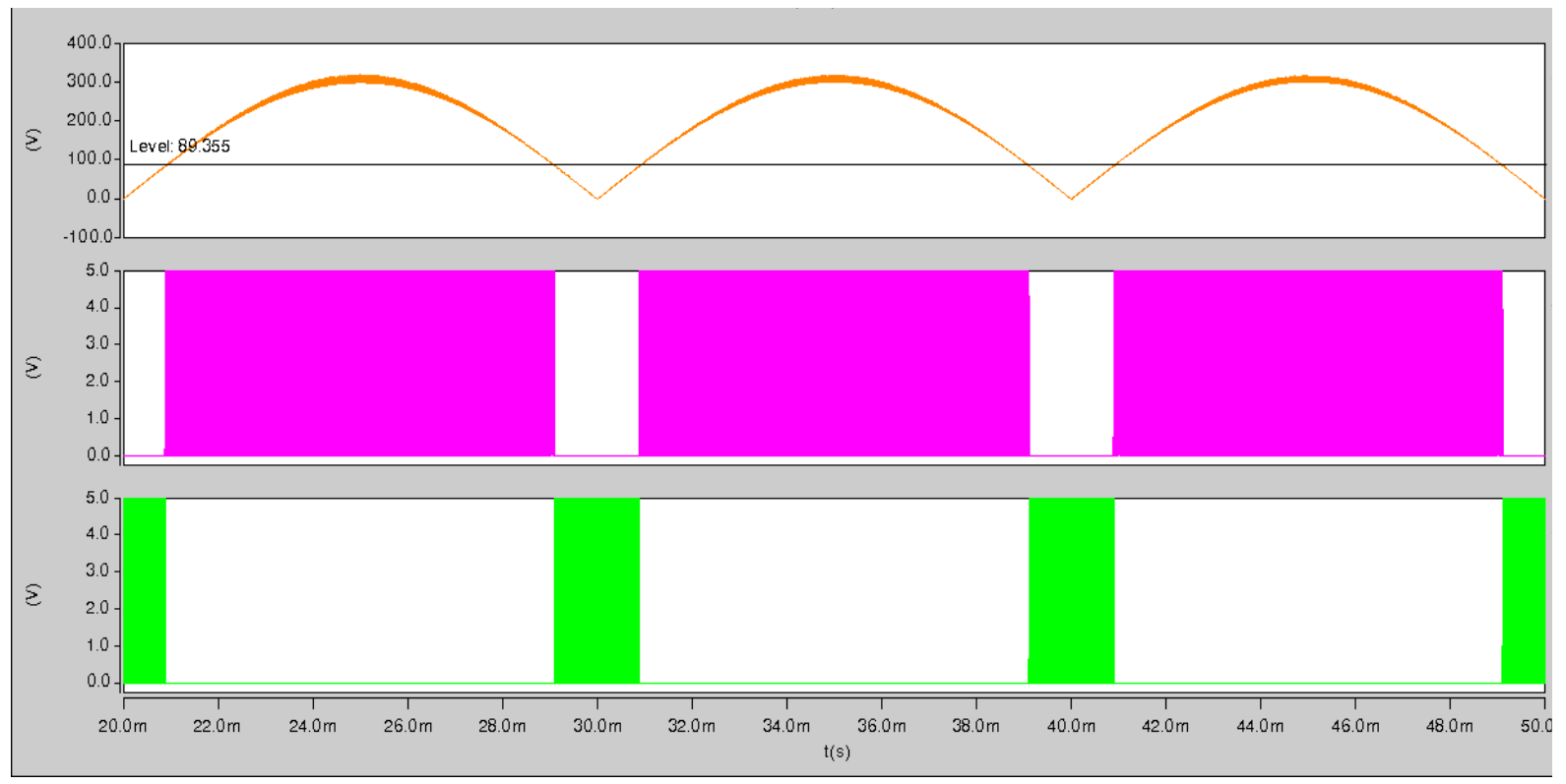

Figure 6. Switches' gate drive signals.

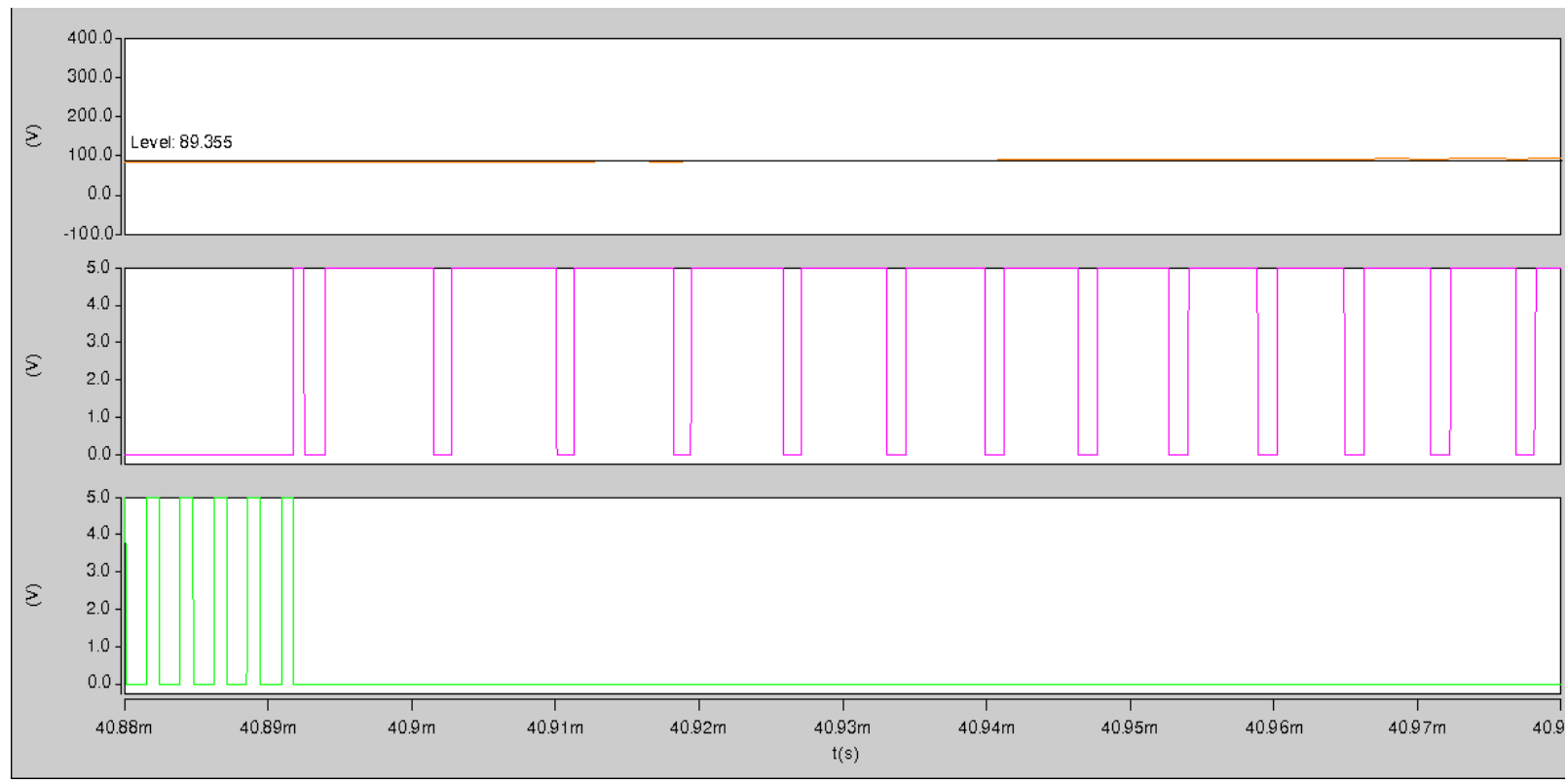

Figure 7. Extended view of Figure 6.

Figure 7 shows the extended view of Figure 6, from which it can be observed that boundary between buck and flyback mode is smooth.

\section{Conclusion}

With constant on-time control, the input PF of integrated buck-flyback converter is low especially at low input voltages. A variable on-time control scheme and the implementation circuit are proposed to realize unity PF at any specific turn's ratio. Simulation results are presented for the verification of the analysis.

\section{References}

1. Limits-Limits for harmonic current emissions (Equipment input current $\leq 16$ A per Phase), IEC. 2014; 61000:3-2.

2. IEEE recommended practice and requirements for harmonic control in electric power systems, of IEEE Standard 519-2014, Revision of IEEE Standard, 2014. 
3. Singh B, Singh S, Chandra A, Al-Haddad K. Comprehensive study of single-phase AC-DC power factor corrected converters with high-frequency isolation, IEEE Transactions on Industrial Informatics. 2011; 7(4):540-56. https://doi. org/10.1109/TII.2011.2166798.

4. García O, Cobos JA, Prieto R, Alou P, Uceda J. Single phase power factor correction: A survey, IEEE Transactions on Power Electronics. 2003; 18(3):749-55. https://doi. org/10.1109/TPEL.2003.810856.

5. Spiazzi G, Buso S. Power factor pre regulators based on combined buck-flyback topologies, IEEE Transactions on Power Electronics. 2000; 15(2):197-204. https://doi. org/10.1109/63.838091.

6. Alonso JM, Dalla Costa MA, Ordiz C. Integrated buckflyback converter as a high-power-factor off-line power supply, IEEE Transactions on Industrial Electronics. 2008; 55(3):1090-1100. https://doi.org/10.1109/ TIE.2007.908530.

7. Dalla Costa MA, Alonso JM, Miranda JC, García J, Lamar DG. A single-stage high-power-factor electronic ballast based on integrated buck flyback converter to supply metal halide lamps, IEEE Transactions on Industrial Electronics. 2008; 55(3):1112-22. https://doi.org/10.1109/ TIE.2007.909729.
8. Gacio D, Alonso JM, Calleja AJ, Garcia J, Rico-Secades M. A universal-input single-stage high-power-factor power supply for HB-LEDs based on integrated buck-flyback converter, IEEE Transactions on Industrial Electronics. 2011; 58(2):589-99. https://doi.org/10.1109/TIE.2010.2046578.

9. Gacio D, Alonso JM, Garcia J, Campa L, Crespo MJ, Rico-Secades M. PWM series dimming for slow-dynamics HPF LED drivers: The high-frequency approach, IEEE Transactions on Industrial Electronics. 2012; 59(4):1717-27. https://doi.org/10.1109/TIE.2011.2130503.

10. Xie X, Zhao C, Lu Q, and Liu S. A novel integrated buckflyback nonisolated PFC converter with high power factor, IEEE Transactions on Industrial Electronics. 2013; 60(12):5603-12. https://doi.org/10.1109/ TIE.2012.2232256.

11. Zhang J, Zhao C, Zhao S, Wu X. A family of single-phase hybrid step-down PFC converters, IEEE Transactions on Power Electronics. 2017; 32(7):5271-81. https://doi. org/10.1109/TPEL.2016.2604845.

12. Memon AH, Yao K, Chen Q, Guo J, Hu W. Variable-on-time control to achieve high input power factor for a CRMintegrated buck-flyback PFC converter, IEEE Transactions on Power Electronics. 2017; 32(7):5312-22. https://doi. org/10.1109/TPEL.2016.2608839. 